\title{
Rankings na educação superior brasileira: uma aproximação aos rankings públicos e privados ${ }^{1}$
}

\author{
Adolfo Ignacio Calderón ${ }^{2}$ \\ Henrique da Silva Lourenço ${ }^{3}$
}

\section{Resumo}

No presente artigo, realizou-se uma aproximação teórica aos rankings acadêmicos, públicos e privados, resultante de pesquisa bibliográfica, na tentativa de compreender sua complexidade e trajetória na realidade brasileira. Defende-se, que as mudanças derivadas da transformação do Estado Provedor para um modelo de Estado Avaliador, reforçaram as tendências em torno das avaliaçôes, índices e classificaçóes por meio de rankings, constatando-se no Brasil, a incipiência de rankings públicos e privados diante da existência de um mercado no qual acabam ganhando legitimidade.

Palavras-chave: Rankings universitários. Avaliação educacional. Educação superior. Universidades. Rankings Acadêmicos.

\begin{abstract}
This article provides a theoretical approach to public and private higher education academic rankings in Brazil aimed towards understanding their complexity and course of development. The paper supports that the changes stemming from the transformation from a Provider State into an Evaluator State model strengthened the trends around assessments through rankings, and it also confirms the incipience of private and public rankings faced with a market scenario where they are ultimately legitimized.
\end{abstract}

Keywords: University Rankings. Educational Assessment. Higher Education. Universities.Academic Rankings.

\footnotetext{
${ }^{1} \mathrm{O}$ presente artigo é uma versão em língua portuguesa, com ajustes, do artigo intitulado, Rankings in brazilian higher education: An approach to public and private rankings (CALDERÓN, LORENÇO, 20I4). Faz parte do projeto de pesquisa intitulado "Rankings acadêmicos do setor privado no Brasil: trajetória e metodologias adotadas numa perspectiva comparada com rankings do espaço ibero-americano”, financiado pelo Conselho Nacional de Desenvolvimento Científico e Tecnológico (CNPq), processo n 310775/20I4-0, coordenado pelo Dr. Adolfo Ignacio Calderón, na condição de Bolsista Produtividade em Pesquisa do $\mathrm{CNPq}$, nível 2, área de Educação.

${ }^{2}$ Doutor em Ciências Sociais pela Pontifícia Universidade Católica de São Paulo com Pós-doutorado em Ciências da Educação na Universidade de Coimbra. É professor titular do Programa de Pós-Graduação em Educação da Pontifícia Universidade Católica de Campinas, Bolsista de Produtividade em Pesquisa do CNPq (Nível 2/Educação). E-mail: <professoradolfocalderon@gmail.com>.

${ }^{3}$ Mestre em Educação pela Pontifícia Universidade Católica de Campinas (PUC-Campinas). Docente no Curso de Pedagogia da Universidade Paulista (UNIP).

Docente no Curso de Direito da Faculdade de Bertioga (FABE). E-mail: <lourenco.hs@gmail.com>.
} 
Introdução

No Brasil contemporâneo, a construção de rankings, índices e classificaçôes, voltados às instituiçôes de educação superior (IES) é parte integrante das políticas públicas de avaliação, principalmente no que tange as avaliaçóes em larga escala, iniciada em 1996, com o extinto Exame Nacional de Cursos (ENC), mais conhecido como "Provão", durante o Governo do Presidente Fernando Henrique Cardoso (FHC). Após a criação do Sistema Nacional de Avaliação da Educação Superior (SINAES), que neutralizava os valores neoliberais associados a cultura de ranqueamento, especificamente no segundo mandato do Presidente Luiz Inácio Lula da Silva (Lula), em 2008, surge o Conceito Preliminar de Cursos (CPC) e o Índice Geral de Cursos (IGC), que retomam a comparação entre instituiçôes universitárias (POLIDORI, 2009; BARREYRO, 2008; ANDRADE, 2011).

Ainda que esses instrumentos de avaliação tenham procedência estatal, com matizes regulatórios, os rankings que envolvem comparaçóes e aspectos numéricos, não podem ser unicamente associados ao Poder Público. Isto porque no caso brasileiro, paralelamente às políticas públicas como "Provão", ENADE (Exame Nacional de Desempenho de Estudante), IGC e CPC, também existem rankings promovidos pelo setor privado, como o Guia do Estudante, publicação criada em 1984 e vigente até a atualidade, caraterizada por classificar as melhores universidades desde 1988, e o Ranking Universitário Folha (RUF) do jornal Folha de São Paulo, criado recentemente no ano de 2012, que se apresentam como um promissor e fértil objeto de estudo para os pesquisadores das ciências sociais. Além disso, convém destacar que no Brasil o primeiro ranking ligado ao mercado editorial estava vinculado a Revista Masculina Playboy, lançado em 1982, e se chamava As Melhores Faculdades do Brasil (CALDERON; MATIAS; LOURENCO, 2014).

Como podemos observar, existe um cenário nacional bastante diversificado no campo das avaliaçóes comparativas na educaçáo superior brasileira, marcado pela presença de rankings privados, oriundos de publicaçôes relacionadas a instituiçôes de natureza comercial, que coexistem com avaliaçóes comparativas provenientes do Poder Público. Neste particular, os estudos realizados por Ordorika e Gómez (2010), ajudam a compreender as distinções entre rankings privados e públicos classificando-os em dois planos, de acordo com suas orientaçóes e finalidades. Em um primeiro plano estão os rankings ligados a critérios acadêmicos, elaborados por governos ou universidades, por instâncias públicas, em um segundo plano, encontram-se os rankings de orientação comercial, publicaçôes não oficiais, que não estão vinculados às políticas dos governos e que se sustentam da venda de publicidade vinculada à divulgação do ranking.

Em relação aos rankings do primeiro plano, aqueles ligados as políticas oficiais do poder público, destaca-se uma bibliográfica aprofundada e diversificada (BRITO 2008; VERHINE, DANTAS, SOARES, 2006; BITTENCOURT, VIALI, RODRIGUES, CASARTELLI, 2010; GOMES, 2003; GOUVEIA, SILVA, SILVEIRA, JACOMINI, BRAZ, 2005; CALDERÓN, POLTRONIERI, BORGES, 2011; CASTRO, 2003; DURHAM, 2003; DURHAM, 2010; DIAS SOBRINHO, 2010B; DIAS SOBRINHO, 2003; LEITE, 2008; REAL, 2009). Diferentemente é a realidade dos rankings do segundo plano, os quais despertam pouco interesse investigativo por parte da comunidade científica. Ao fazer levantamentos no Banco de Teses da Coordenação de Aperfeiçoamento de Pessoal de Nível Superior (CAPES), no Banco de Teses da Universidade de São Paulo (USP), no Banco de Teses da Universidade Estadual de Campinas 
(UNICAMP) e no portal da biblioteca virtual Scientific Eletronic Library Online (Scielo), a respeito das pesquisas feitas sobre os rankings privados como o Guia do Estudante e os das revistas Playboy, observou-se apenas uma dissertação, em 2014, sobre os rankings do Guia do Estudante (LOURENÇO, 2014), bem como reduzido número de artigos científicos (ANDRADE, 2011; ANDRADE, MOITA, LOBO e SILVA, 2009; CALDERON, MATIAS, LOURENCO, 2014; SETTON, 2005; ODORIKA e GOMEZ, 2010).

Diante da escassa produção científica a respeito dos rankings oriundos do setor privado, o presente artigo, a partir de uma pesquisa bibliográfica-exploratória, realiza uma aproximação teórica aos rankings públicos e privados na educação superior brasileira, tendo como objetivo compreender a complexidade e a trajetória deles à luz das mudanças produzidas pelo processo de reforma do Estado e de sua correspondente transiçáo de um Estado provedor para um Estado avaliador. Defende-se a tese de que, no Brasil, a institucionalização do Estado avaliador reforçou as tendências de expansão da avaliação por meio de rankings, propagando-se políticas transnacionais que acentuam e potencializam os mercados de educação superior, os quais legitimam o funcionamento de rankings como forma de diferenciação institucional.

\section{Os rankings acadêmicos no contexto da reforma do Estado}

A trajetória das políticas de avaliação da educação e, por consequência, a presença de rankings na avaliação da educação superior, em linhas gerais, se vincula às mudanças e reformas nas estruturas dos Estados e aos movimentos de globalização e tecnológicos.

Nas políticas sociais como a educação, saúde e previdência, ou mais especificamente, no campo das políticas de avaliação da educação superior e na administração universitária, pública e privada, surgem certas tendências que devem ser observadas sob a ótica da reforma do Estado. Tratam-se de fenômenos posteriores à crise da década de 1970, que aproximam o Estado ao setor privado por meio da assimilaçáo de lógicas relativas à economia, a competição e a dinâmica de mercado, retrato da crise do keynesianismo e da crise fiscal do Estado, que culminou com a eleição de governos conservadores em países basilares no cenário mundial, exemplos de democracia consolidada e industrialização avançada, como a Inglaterra, com Margaret Thatcher, e os Estados Unidos da América (EUA), com Ronald Reagan, ambos nos anos 80 (KING, 1988; ANDERSON, 1995; e ABRUCIO, 2005).

Antes do período reformista, consolidado na década de 1980, as estruturas de proteção social acompanharam o crescimento econômico, a chamada "Era Dourada" da economia, que ocorreu nos anos 50 e 60 do século passado, período de exaltaçáo do Welfare State como modelo social de Estado, do keynesianismo como modelo econômico e da burocracia Weberiana como modelo administrativo (ABRUCIO, 2005).

Neste sentido, em artigo contemporâneo aos governos de Thatcher e Reagan, King (1988), sinaliza os graus de resistência dos Estados industriais avançados e de regimes democráticos consolidados, com relação à iminente redução de suas estruturas de Welfare State, por meio de políticas reformistas. Para King, os Estados de Bem-Estar "maduros têm suas estruturas e benefícios entrelaçados às estruturas sociais que eles próprios remodelaram" o que institucionaliza a proteção social (1988, p. 53). Evidentemente, não é o caso do Brasil e da América Latina, com exceção de alguns países que apresentam satisfatórios índices de proteção social 
(DRAIBE, 1997). Nestes termos, é pertinente a introdução ao artigo Educação e bem-estar social que ressalta o caráter embrionário das estruturas de Bem-Estar Social no Brasil (PAIVA, 1991). Semelhantemente, King (1988), empregou o termo marginal ao se referir as estruturas de Welfare State da América Latina.

É conveniente ressaltar que no caso brasileiro, a consolidaçáo de direitos e de conquistas no plano da proteçáo social, em termos legais e otimizados, se deu apenas em 1988 com a promulgaçáo da Constituição Federal (CF) e a consequente democratização do país, ocasião em que a crise fiscal, os processos de globalização e os movimentos de reforma do Estado e de sua burocracia, estavam em pleno vapor na Europa e nos Estados Unidos (ANDERSON, 1995; PAIVA, 1991).

Para o modelo de bem-estar social, a educação corresponde a concepção associada a dimensão pública (DRAIBE, 1997), de caráter estatal. Sem embargo, esta concepção se viu diante de uma mudança de interpretação que afetou as estruturas de proteção social dos Estados, devido ao fato de a educação passar a ser concebida como um serviço dentro de um mercado educacional. Desta forma, durante os processos de reforma do Estado, alguns autores ressaltaram o surgimento e expansão, na Europa e no mundo globalizado, de um modelo de universidade anglo-americana, resultante das reformas do Estado provedor, impregnado de concepçóes liberais e transnacionais (LIMA; AZEVEDO; LIMA, 2008).

Para Lima, Azevedo e Catani (2008), a transnacionalização das políticas se intensificou fortemente com a Declaração de Bolonha, no final dos anos 90, declaração esta que objetivava o estabelecimento de um espaço europeu de educaçáo superior totalmente integrado - apesar das grandes diferenças existentes entre os países membros da Uniáo Europeia $(\mathrm{EU})$-, à uma lógica de competitividade dentro da própria EU e fora dela, principalmente com o espaço estadunidense de educação superior.

O Processo de Bolonha ficará para a história como um processo político fortemente governamentalizado em termos nacionais, no contexto de certos países, e extremamente sobredeterminado por agendas transnacionais. Voluntariamente nenhum governo nacional parece disposto a ficar fora do processo, preferindo aderir, mesmo quando as consequências da criação de um sistema europeu altamente competitivo e internacionalmente avaliado, curso a curso, instituição por instituição, país por país, venham provavelmente a produzir resultados dramáticos para alguns dos participantes como, aliás, exige a lógica de emulação do tipo mercantil, com a correspondente criação de mercados externos e internos (LIMA, AZEVEDO, CATANI, 2008, p. 13).

De acordo com Lima, Azevedo e Catani (2008), o processo de Bolonha possibilitou a existência de um movimento de "convergência normativa" no espaço comum europeu, com a finalidade de formar um sistema sujeito as mesmas orientações e regras, que permitisse que a competição interna funcionasse de acordo com critérios comuns e comparáveis. Trata-se de um sistema de convergências que acaba por criar as bases para um cenário competitivo e de mercado, marcado pela regulação, pelas informaçóes dos serviços aos consumidores e por uma avaliação contínua da qualidade. 
Frente ao avanço da lógica do capital, nas décadas de 1980 e 1990, se configurou um cenário no qual as políticas de avaliação buscavam garantir e regular a qualidade dos serviços oferecidos, suscitando o surgimento da ideia de quase-mercado, cristalizada na alteração do curso seguido pelas políticas educacionais (SOUZA e OLIVEIRA, 2003). Neste sentido, Laval (2004), considera os EUA e a Inglaterra como representantes do ideal liberal de mercado, países nos quais a ideologia do livre mercado encontrou seu terreno clássico de aplicação antes de se difundir universalmente. Laval (2004) destaca que durante o programa eleitoral do governo Reagan, em 1980, por exemplo, prometia-se:

Desregulamentação da educação pública, a eliminação do departamento federal de educação e supressão do transporte escolar público. As escolas deviam se transformar em empresas com fim lucrativo na medida em que a eficiência do mercado seria presumidamente capaz de melhorar o acesso à educação e à qualidade de ensino, desembaraçando-o dos regulamentos burocráticos e dos sindicatos (LAVAL, 2004, p. 91).

No Brasil, todo esse processo de expansão dos princípios liberais representou uma ruptura de paradigma, na medida em que a questáo referente à ideologia do livre mercado foi atingindo espaços cada vez mais antagônicos, como por exemplo, a universidade. Ao abordar a inserção das universidades públicas brasileiras, como a Universidade de São Paulo (USP) e a Universidade Federal do Rio de Janeiro (UFRJ), à “[...] lógica racionalizadora do capital”, de Paula (2001, p. 15), apresenta uma abordagem crítica quanto ao processo de modernização das universidades públicas e coloca a Reforma Universitária de 1968 como ponto de partida para a "diluição do papel clássico da universidade" no Brasil.

Em abordagem diferente, Helena Sampaio (2000) ressalta que a reforma universitária de 1968, apesar de promovida pelo governo ditatorial, significou modernização e dinamismo, proporcionando ao sistema de educação superior a possibilidade de alinhar-se às inúmeras bandeiras do movimento estudantil, como a abolição da cátedra e a institucionalização da pesquisa científica. Nesta mesma perspectiva, Calderón (2000) refere-se à Reforma Universitária de 1968 como uma política de modernização e reestruturação do sistema universitário, que fez com que a educação superior abandonasse uma concepção pública (estatal) e adotasse uma postura mais flexível vinculando-se gradualmente e, com mais força nos anos 1990, à lógica de universidades privadas com fins lucrativos, voltadas ao ideal empresarial e ao mercado.

As modificaçôes em relação ao papel desempenhado pelo Estado diante de sua crise fiscal, iniciada na década de 1970 e agravada nos anos 1980, foram operadas a partir do processo de reforma gerencial nas estruturas de Bem-Estar Social, as quais também foram visíveis no âmbito das universidades. Ao contrário do que aconteceu com os outros países da América do Sul que massificaram suas universidades públicas, o Brasil (e também o Chile), optou por manter uma universidade pública de elite, voltada para pesquisa e para critérios de seleção de alunos, incentivando paralelamente um sistema universitário de massa composto por universidades privadas de qualidade duvidosa (CALDERÓN, 2000).

As décadas de 1970 e 1980, todavia expressavam a hegemonia das universidades públicas no cenário da educaçáo superior nacional. No entanto, a partir da década de 1990, com o surgimento de uma enorme quantidade de universidades privadas - fruto das opçóes políticas da Reforma Universitária de 1968, das 
dinamizaçóes possibilitadas pela Constituição Federal de 1988, de múltiplas pressóes advindas das agências multilaterais impulsionadoras das políticas neoliberais em nível global, dos empresários da educação e da população que pretendia acesso a serviços educacionais -, tornou-se explícito o princípio da concorrência entre as universidades brasileiras, principalmente do setor privado (CALDERÓN, 2000).

Diante desta realidade, Dias Sobrinho (2004) ressalta que a educaçáo superior vive uma espécie de rompimento de paradigma:

[...] a educaçáo superior tem sido considerada uma instituição que produz conhecimentos e forma cidadãos para as práticas da vida social e econômica, em benefício da construção de naçóes livres e desenvolvidas. Em posição distinta, cresce e se fortalece hoje a defesa da educação superior como função da economia e dos interesses individuais e privados. Essas diferenças ideológicas relativas ao papel social da educaçáo superior interferem fortemente na compreensão das funções da avaliação (DIAS SOBRINHO, 2004, p. 704).

Nessa perspectiva, o papel social da educaçáo superior reveste-se de diferenças ideológicas que interferem na compreensão e definição das finalidades da avaliação para a educação. Para Dias Sobrinho (2004, p. 704), existem "aqueles que vêm à escola como uma instituiçâo constitutiva da República e querem que a escola forme o cidadáo" e existem aqueles "que vêm à escola como uma empresa, num vasto mercado de formaçáo" (DIAS SOBRINHO, 2004, p.704). Para esse autor, "não há consenso sobre avaliação em geral e tampouco existem muitos acordos sobre o que seja hoje a educação superior e, sobretudo, quais são as suas funções mais importantes na sociedade" (DIAS SOBRINHO, 2004, p.705). Trata-se de uma disputa desigual, segundo Laval (2004, p. 91), que legitimou a educação como "[...] objeto de escolha em um mercado livre" devido ao "sucesso político do neoliberalismo nos anos de 1980".

Juntamente com as novas concepçóes que determinam as funções do Estado - que passou de provedor a fiscalizador-avaliador -, o cidadão é entendido como cliente e consumidor. Os sistemas e instrue mentos de avaliação, estatais e privados, se estabeleceram como indicadores de qualidade e produção das universidades em um cenário de competição, de proximidade às lógicas de mercado e de interferência de políticas transnacionais. Sáo todos esses elementos que dão margem e espaço para o debate em torno das formas de implantação e da importância de políticas avaliadoras (GOUVEIA; SILVA; SILVEIRA; JACOMINI; e BRAZ, 2005).

A mudança de um modelo de Estado Provedor para um Estado Fiscalizador significa a mudança de um modelo de Estado Interventor para um Estado Avaliador (GOMES, 2002), acabando por fomentar, ao redor do mundo e obviamente no Brasil, o desenvolvimento de avaliaçóes de ordem numérica e quantitativa, de origem pública ou privada, centradas no princípio regulador, no caso do Estado, e também no princípio da competição, principalmente no caso da iniciativa privada, ainda que existam exemplos de políticas estatais direcionadas à competição e a publicidade do desempenho institucional como elementos indutores de qualidade. 


\section{0 surgimento e a coexistência de rankings acadêmicos públicos e privados}

Durante a década de 1980, emergiram no Brasil pioneiras iniciativas no campo da avaliaçáo da educaçâo superior como o Programa de Avaliação da Reforma Universitária (PARU) e o relatório do Grupo Executivo para a Reforma da Educação Superior (GERES), as mesmas que representaram posturas e tendências político-ideológicas diferentes. De acordo com Barreyro e Rothen (2008), a primeira foi uma iniciativa estatal, que considerava necessária a participação da comunidade acadêmica objetivando um processo de reflexão sobre sua própria prática, por meio de mecanismos de auto avaliação. A segunda, com ênfase tecnicista, propunha a regulação e o controle das universidades de forma não burocrática, por meio de processos de avaliaçáo direcionados a identificar o desempenho institucional. Esta última propunha também: (i) a diversificação institucional das universidades - instituições de investigação e de formação profissional -, (ii) a possibilidade de existirem universidades especializadas em áreas do conhecimento exclusivas - desta forma não contemplariam as diferentes áreas do conhecimento - e (iii) a vinculação do financiamento da universidade ao desempenho institucional.

A partir destas iniciativas, marco inicial das políticas de avaliação em tempos de mudança do papel do Estado, é possível traçar uma rota histórico-evolutiva da trajetória da avaliação na educação superior no Brasil, composta por quatro ciclos, conforme analisou Polidori (2009). No primeiro ciclo, 1983 a 1992, ocorreram tentativas de viabilização de um processo de avaliação, que culminaram com a implantação do PARU e do GERES. O segundo ciclo, de 1993 a 1995, caracteriza-se pela formulação de políticas como o Programa de Avaliação Institucional das Universidades Brasileiras (PAIUB) que, conforme especificaram Barreyro e Rothen (2008), entendia as avaliaçóes como atos políticos e voluntários das instituiçóes com o objetivo de prever seu projeto acadêmico e social a partir da auto-avaliaçáo, dentro de uma perspectiva formativa e emancipadora não destinada a punir ou premiar. O terceiro ciclo, 1996 a 2003, se concretizou durante o Governo FHC, por meio da elaboraçâao do "Provão" ou ENC, primeiro instrumento que previa o ranqueamento estatal dos cursos oferecidos por instituiçóes de educaçáo superior, amplamente divulgado pelos meios de comunicaçáo e elaborado a partir do desempenho dos estudantes.

Para Polidori (2009), o quarto ciclo teve início em 2004 durante o primeiro mandado do Presidente Lula, com a criação do Sistema Nacional de Avaliação da Educação Superior (SINAES), que apesar de contemplar um instrumento de avaliação dos estudantes, o ENADE, se baseava em uma proposta formativa e emancipadora, tentando erradicar iniciativas consideradas neoliberais implantadas durante o Governo FHC, que propagavam a "hipervalorização da competitividade entre instituiçóes educacionais e os rankings com ampla divulgação da imprensa" (CALDERÓN; POLTRONIERI; BORGES, 2011, p. 815).

Analisando a história recente da avalição da educação superior brasileira, Molck (2013) complementa os ciclos sistematizados por Polidori (2009) ao afirmar que o quarto ciclo se encerrou em 2007, com a criação do IGC, índice que permitiu o ranqueamento promovido diretamente pelo Governo, retomando princípios governamentais dos tempos de FHC. Diante dessa realidade, Molck (2013) considera o início de um quinto ciclo, que se caracteriza por meio da avaliaçáo para a regulaçáo implicando, a partir de 2007, em mudanças na estrutura legal e nas diretrizes da gestão pública ao valorizar a avaliação por resultados, desenvolvendo políticas para fortalecer a capacidade gerencial do governo, por meio de políticas de regulação do sistema. 
É conveniente lembrar que a partir do terceiro ciclo descrito por Polidori (2009), durante o Governo FHC, deu-se início a uma ampla reforma na administraçáo pública como resposta a crise fiscal do Estado nos anos 1980. Bresser-Pereira (1996, p.1), então Ministro da Reforma do Estado, respondeu as pressóes impostas por força da globalizaçáo e da crise gerencial do Estado ressaltando que, tanto uma como a outra, "estão impondo, em todo o mundo, a redefinição das funções do Estado e de sua burocracia". No embalo das reformas, o Ministério da Educação do Governo FHC, comandado pelo Ministro Paulo Renato, apresentou ao país o ENC, primeiro grande ranking oficial que representou uma ruptura com a política de avaliação do PAIUB, predominante à época e pautada na chamada avaliação emancipatória (GOMES, 2003).

Como consequência, a avaliação por rankings foi ganhando espaço não somente entre as universidades particulares, onde já era esperado um enorme uso principalmente publicitário dos bons resultados, mas também, entre as universidades públicas, que não hesitaram em utilizar suas pontuações obtidas no ranking do "Provão" como discurso publicitário e de status acadêmico (BARREYRO, 2008; TUYAMA, 2011).

Com o "Provão" iniciou-se um período marcado por avaliaçóes comparativas/rankings entre as instituiçôes, competitividade no mercado educacional e no mercado do prestígio. Esta foi uma etapa caracterizada pela presença acentuada de elementos numéricos e matemáticos no âmbito educacional, dentro de uma lógica quantitativa de mercado. Depois dos dois mandatos do Governo FHC, durante o Governo Lula, criou-se o SINAES e consequentemente o ENADE, na tentativa de alternar a dinâmica das políticas de avaliação, deixando de lado a classificação/ranking (o "Provão" ou ENC). Desta forma extinguiu-se o ENC. Tanto o SINAES quanto o ENADE foram aclamados e enquadrados em uma perspectiva emancipatória (BRASIL, 2004).

Apesar da extinção do ENC, a busca por rankings e a sedução que seus resultados causavam nos meios de comunicação pareciam não acabar. Depois da criação do SINAES, o ENADE foi explorado pela imprensa como se fosse um ranking, fato prontamente rechaçado por seus formuladores sob a alegação de que o ENADE unicamente compóe o sistema de avaliação (SINAES) e não deveria ser interpretado ou utilizado de modo isolado (DIAS SOBRINHO, 2010-a). Neste sentido, Fiamini e Calderón (2012), ao investigarem o ENADE a luz da cobertura da Folha de São Paulo, ressaltaram que a imprensa se impregnou de tal forma, com a cultura de avaliação comparativa (rankings) instituída no Governo FHC, que tentava, logo no inicio do SINAES, criar, sem sucesso, rankings a partir do ENADE. Deve-se registrar que o ENADE, entre outros aspectos, diferenciava-se do ENC por estar focado na identificação do valor agregado pelo curso na formação do aluno, sendo aplicado, dentro de um ciclo avaliativo, com intervalo de três anos, a amostras significativas de iniciantes e concluintes, comparando as respostas dos dois grupos de estudantes. Nesta ótica, o ENADE não permitira o ranquamento, uma vez que possuía um caráter formativo e não classificatório.

No segundo mandato de Lula houve a criação do CPC e do IGC, no ano de 2008. Estes dois elementos deram origem a um novo ranking das instituições de educação superior, gerando contradições em relação ao real papel do SINAES, sistema até então centralizador na regulação da avaliação da educação superior (ANDRADE, 2011; POLIDORI, 2009; BARREYRO, 2008; CALDERÓN; POLTRONIERI; BORGES, 2010).

Como se pode observar, todas as ações governamentais descritas representam iniciativas públicas (estatais) de avaliaçáo por meio de rankings, sendo a primeira delas implementadas em 1996, por meio do "Provão". Diferentemente dos países anglo-saxôes, nos quais as avaliaçôes por rankings privados possuem 


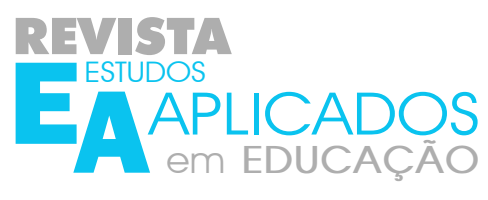

um enraizamento cultural maior (ORDORIKA e GOMÉS, 2010), no Brasil o ranqueamento da educação superior enfrenta focos de resistência, o que torna o processo incipiente. Ainda que os rankings privados no país datem da década de 1980, quando foi criado o Ranking das Melhores Faculdades do Brasil, promovido pela Revista Masculina Playboy, a experiência brasileira pode ser considerada incipiente tendo em vista as interrupçóes e descontinuidades das políticas públicas, o que não permitiu o enraizamento dos rankings na cultura brasileira.

Anteriormente às políticas públicas oficiais, pautadas na comparação entre as universidades (ENC, ENADE - IGC e CPC), conforme analisa Fabrício Marques (2009), em seu artigo escrito para a Revista Pesquisa da Fundação de Amparo à Pesquisa do Estado de São Paulo (FAPESP), "a popularização dos rankings é um fenômeno recente. No Brasil, até a década de 1990, o mais conhecido ranking de universidades do país era feito por uma revista masculina, a Playboy" (MARQUES, 2009).

O artigo intitulado, Universidade aparece em primeiro lugar em avaliação feita pela revista Playboy (UNIVERSIDAD ESTADUAL PAULISTA JÚLIO DE MESQUITA FILHO, 2000), ao tratar dos resultados obtidos pela Universidade Estadual Paulista Júlio de Mesquita (UNESP) no ranking da revista Playboy, destacou o bom desempenho obtido em três rankings promovidos pelo setor privado: Playboy, Revista Época? e Guia do Estudante. Evidentemente, o ranking da revista Playboy e a iniciativa da Revista Época não estão mais em vigêne cia restando, atualmente, a publicaçáo Guia do Estudante e o RUF do Jornal Folha de São Paulo.

Como destacaram Ordorika e Gómez (2010, p.10), os rankings não oficiais - produzidos pelo setor privado: empresas editoriais, meios de comunicação, grupos de consultoria - integram um movimento pautado na formação de mão-de-obra qualificada e especializada, no estímulo a concorrência e a competição entre as universidades, um movimento de internacionalização das instituições acadêmicas. No setor privado, o extinto ranking da Revista Playboy reinou absoluto no cenário educacional na década de 1980, sendo que, na década de 1990, o referido ranking passou a conviver, no mesmo mercado, com o Guia do Estudante que também produzia rankings publicados de forma contínua e regular. Com a extinçâo do ranking da revista masculina em 2000, os rankings produzidos pelo Guia do Estudante passaram a ser a única referência de ranqueamento universitário ao longo da primeira década do século XXI, acumulando mais de 25 anos de experiência, passando a conviver, desde 2012, com o recém-criado RUF.

Ao pesquisar a comunicação, divulgação e difusão institucional das universidades no tocante ao Prêmio Melhores Universidades do Guia do Estudante de 2011, elaborado pelo ranking do Guia do Estudante que premiava as melhores universidades com maior quantidade de estrelas, se verificou que tanto universidades públicas como privadas utilizam tais dados de publicidade a respeitos de seus bons desempenhos (HENRIQUE, 2011; CENTRO UNIVERSITÁRIO DO CERRADO PATROCÍNIO, 2011, TUYAMA, 2011).

Neste particular, a avaliação de cursos superiores promovida pelo Guia do Estudante não passa despercebida, e os bons resultados surtem efeitos perante os diversos segmentos da educação superior brasileira. Alguns destes efeitos são sentidos no âmbito da comunicação institucional e podem ser observados por meio de matérias que celebram e justificam os bons resultados. Neste sentido, a professora Dione de Oliveira Moura, da Faculdade de Comunicação da Universidade de Brasília (UNB), destaca: 
O resultado da publicação, sem dúvidas, é um sinal de que estamos caminhando no rumo certo. Os investimentos em formação de docentes, reformas laboratoriais e curriculares e o fortalecimento das práticas em nosso Laboratório de Jornalismo são uma amostra disso. Também os nossos alunos desempenham um papel importante diante dos resultados, sendo críticos e participantes. Temos um curso maduro que tratamos como se fosse um curso novo, nunca achamos que está bom, sempre estamos reinventando. Essas cinco estrelas representam isso (UNIVERSIDADE DE BRASÍLIA, 2011, p.1).

Outro exemplo é o discurso da pró-reitora de graduação da USP, Telma Maria Zorn, que ressalta o processo realizado em direção aos bons resultados, ao afirmar que para "[...] manter essa excelência fazemos avaliaçôes constantes, internas e externas, e estabelecemos metas, sempre tentando superá-las" (GUIA DO ESTUDANTE, 2011, p. 1).

No segmento particular de educação, por sua vez, também se encontram tais discursos: a Universidade Braz Cubas (UBC) coloca o Guia do Estudante como "[...] uma publicação que reconhece a qualidade do ensino superior público e privado" (UNIVERSIDADE BRAZ CUBAS, 2012, p. 1). A Universidade do Norte do Paraná (UNOPAR), universidade pioneira, autointitulada líder do segmento ensino à distância com 120 mil alunos (UNIVERSIDADE DO NORTE DO PARANÁ, 2011), também ressalta o desempenho obtido no Guia do Estudante. Para Hélio Rodolfo Navarro, vice-reitor da instituição, "[...] o trabalho que vem sendo desenvolvido está gerando frutos. O fato de termos 18 cursos no rol dos estrelados já demonstra o diferencial de qualidade dos cursos da Unopar" (UNIVERSIDADE DO NORTE DO PARANÁ, 2011, p. 1).

No campo das universidades confessionais, a tradicional Pontifícia Universidade Católica de São Paulo divulgou em seu portal de internet os resultados do ranking de 2010, com o título "Orgulho de ser PUC. PUC-SP vence premio Melhores Universidades do Guia do Estudante" (PONTIFICIA UNIVERSIDAD CATÓLICA DE SÃO PAULO, 2010, p. 1), destacando as estrelas recebidas pela qualidade de 25 cursos. Outras universidades também comemoram, é o caso da Universidade Metodista de São Paulo. Segundo Ana Maria Santana Martins, coordenadora do curso de Secretariado Executivo Bilíngue da Metodista, o resultado no Guia do Estudante "[...] representa o amor, a dedicação e o comprometimento que a coordenação, o corpo discente, docente, direção e todo setor administrativo da Instituição tem tido para com o nosso curso" (METODISTA, 2011, p. 1).

Como se observa, trata-se de instituições de naturezas jurídicas diferentes (estatais, filantrópicas e privadas) que expressam discursos semelhantes no sentido de atribuir legitimidade e confiança aos resultados da publicação Guia do Estudante, sem questionar os procedimentos metodológicos adotados. A presença no cenário nacional de uma publicação como o Guia do Estudante e mais recentemente o RUF, representa um fenômeno que já havia ocorrido em países anglo-saxônicos algumas décadas antes, do qual o grande exemplo é o ranking universitário Times, World University Ranking Times Higher Education (THES), antes vinculado formalmente ao influente jornal inglês The Times (ORDORIKA; GÓMEZ, 2010). 


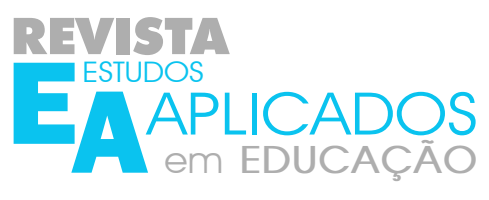

\section{Observações finais}

Com o presente artigo realizou-se uma aproximação teórica dos rankings públicos e privados da educação superior brasileira, bem como, se buscou estabelecer proximidades e compreender a complexa trajetória dos ranqueamentos, em um contexto marcado pela transição de um Estado provedor para um modelo de Estado avaliador, cenário que acabou por reforçar as tendências em torno das avaliaçóes numéricas e comparativas dirigidas a oferecer suporte instrumental cristalizado na figura dos rankings.

Entre outras conclusôes aos quais conseguimos chegar, tem-se uma realidade inquestionável: no Brasil coexistem rankings acadêmicos públicos (estatais) e privados, fato que não pode ser menosprezado na compreensão da complexidade da educação superior. Trata-se de um cenário no qual se configuram instrumentos de avaliação voltados a mensurar a qualidade educativa, em uma perspectiva classificatória, sustentados no princípio da competitividade, como forma de distinção entre as IES que atuam na educação superior. Nesta ótica, os rankings do setor privado estariam direcionados para o esclarecimento e a transparência de informaçóes para os futuros alunos, agora também chamados de cidadãos-consumidores, os quais teriam maiores elementos para realizarem suas escolhas no mercado educacional. Por sua vez, os rankings estatais estariam direcionados para a regulaçấo da educação superior, imprimindo parâmetros de qualidade, possibilitando a responsabilização em termos de transparência da qualidade dos serviços públicos como mecanismo de controle social, podendo potencialmente subsidiar as escolhas dos futuros estudantes universitários.

Como se pode observar, é um cenário que, ao largo das últimas décadas, foi construído por meio de disputas de projetos políticos e ideológicos em relação à necessidade e importância da avaliação do sistema de educação superior brasileira. Desde a década de 1980, quando surgiram as primeiras iniciativas estatais de avaliação das universidades, bem como o primeiro ranking acadêmico do setor privado, sempre existiram tensões entre o que Santos (1995) denomina pilar da emancipação e o pilar da regulação. A existência do quinto ciclo, mencionado por Molck (2013), demonstra a legitimidade no âmbito governamental da avaliação para a regulação, sustentada em um dos pilares da nova administração pública: a avaliação por resultado.

Apesar da existência de governos com perfis políticos e ideológicos diferentes e das promessas de redenção da esquerda latino-americana, realizadas pelo governo Lula, apregoando contras as políticas neoliberais, podemos afirmar que as políticas públicas, nos últimos 30 anos, convergiram na avaliação para a regulaçáo como meio de dinamizar o mercado da educação superior que, no Brasil, de acordo com o Censo da Educação Superior de 2010 (MINISTÉRIO DA EDUCAÇÃO, 2012), concentra $74,2 \%$ das matrículas de graduação em IES do sector privado. Trata-se de mais de 2100 IES privadas, $88,3 \%$ do total de IES da educação superior brasileira, que atende 4.736 .001 alunos, contra 278 IES públicas que atendem a 1643298 alunos, as quais tomam como principais parâmetros de qualidade os índices e classificaçôes governamentais, sendo que muitas delas também comemoram, periodicamente, as estrelas de qualidade oferecidas por rankings privados, como o Guia do Estudante, bem como o lugar ocupado no Ranking da Folha de São Paulo. 


\section{Referências}

ABRUCIO, F. Os avanços e os dilemas do modelo pós-burocrático: a reforma da administração pública à luz da experiência internacional recente. In: BRESSER-PEREIRA, L. C.; SPINK, P. (orgs.). Reforma do Estado e Administraçáo Pública Gerencial. 7. ed. Rio de Janeiro: Editora Fundação Getúlio Vargas, 2005.

ANDERSON, P. Balanço do neoliberalismo. In: SADER, E.; GENTILI, P. (orgs.) Pós-neoliberalismo: as políticas sociais e o Estado democrático. Rio de Janeiro: Paz e Terra, 1995, pp. 09-23.

ANDRADE, E. de C. Rankings em Educação: tipos, problemas, informaçôes e mudanças: análise dos principais rankings oficiais do Brasileiros. Estudos Econômicos, São Paulo, v.41, n. 2, p.323-343, junho, 2011.

ANDRADE, E. de C.; MOITA, R.; LOBO e SILVA, C. E. (2009). A escolha da faculdade pelo aluno: estimação da demanda e precificação dos atributos. Insper Working Paper, São Paulo, n. 182, 2009.

BARREYRO, G. B. De exame, rankings e mídia. Avaliaçáo, Campinas; Sorocaba, SP, v.13, n. 3, p.863868, nov.2008.

BARREYRO, G. B; ROTHEN, J. C. Política de avaliação e regulaçáo da educação superior brasileira. VII Congresso Luso-Brasileiro de História da Educação, Porto. Anais do VII Congresso Brasileiro de História da Educaçáo. Porto: Universidade do Porto, p. 1-18, 2008.

BITTENCOURT, H. R.; VIALI, L.; RODRIGUES, A. C. de M.; CASARTELLI, A. de O. Mudanças nos pesos do CPC e seu impacto nos resultados de avaliação em universidades federais e privadas. Avaliaçáo, Campinas, v.15, n.3, p.147-166, 2010.

BRESSER-PEREIRA, L. C. Da administração pública burocrática à gerencial. Revista do Serviço Público, v.47, n.1, janeiro-abril, 1996.

BRITO M. R. F. O Sinaes e o Enade: da concepção à implantação. Avaliaçáo, Campinas, SP, v. 13, n. 3, p. 841-850, nov. 2008.

CALDERON, A. I. Universidade Mercantil: a institucionalização do mercado universitário em questão. Sáo Paulo em Perspectiva, v. 14, n. 1, São Paulo, 2000.

CALDERON, A. I.; LOURENCO, H. S. Rankings en la educación superior brasileña: una aproximación a los rankings públicos y privados. Revista Digital de Investigación en Docencia Universitaria, v. 8, p. 95-110, 2014.

CALDERON, A. I.; MATIAS, R. C.; LOURENCO, H. S. Rankings na Educação Superior: as melhores faculdades do Brasil (1982-2000). Estudos em Avaliaçáa Educacional, v. 25, p. 226-247, 2014.

CALDERON, A. I.; POLTRONIERI, H. e BORGES, R. M. Avaliação, rankings e qualidade da educação superior. Revista Estudos, v.19, n.39, pp. 103-109, 2010.

CALDERON, A. I.; POLTRONIERI, H.; BORGES, R. M. Os rankings na educação superior brasileira: políticas de governo ou de estado?. Ensaio: Avaliação e Políticas Públicas em Educação, v.19, n.73, pp. 813-826, 2011. 
CASTRO, M. H. G. Quem tem medo do Provão? Jornal da Ciência, São Paulo, 29 set. 2003. Disponível em: <http://www.jornaldaciencia.org.br/Detalhe.jsp?id=13126>. Acesso em: 26 set. 2010.

CENTRO UNIVERSITÁRIO DO CERRADO PATROCÍNIO. Cursos promovem carreata em comemoração a resultado do Guia do Estudante 2011. 13 de set., 2011. Disponível em: <http://www.unicerp. edu.br/index.php?option=com>. Acesso em: 08 out. 2013.

DIAS SOBRINHO, J. Avaliaçáo: políticas educacionais e reformas da Educação Superior. São Paulo: Cortez, 2003.

DIAS SOBRINHO, J. Avaliação ética e política em função da educação como direito público ou como mercadoria? Educação \& Sociedade, Campinas, v. 25, n. 88, p. 703-725, 2004.

DIAS SOBRINHO, J. Qualidade, avaliação: do Sinaes a índices. Avaliaçáo, Campinas; Sorocaba, SP, v. 13 , n 3, p. 817-825, 2010a.

DIAS SOBRINHO, J. Avaliação e transformação da Educação Superior Brasileira (1995-2009): do Provão ao Sinaes. Avaliaçáo, Campinas; Sorocaba, SP, v. 15, n. 1, p. 195-224, 2010 b.

DURHAM, E. O Provão deve ser extinto? Não. Jornal da Ciência, São Paulo, 8 set. 2003. Disponível em: <http://www.jornaldaciencia.org.br/Detalhe.jsp?id=12577>. Acesso em: 02 mar. 2011.

DURHAM, E. A política educacional do governo Fernando Henrique Cardoso: uma visão comparada. Novos Estudos: CEBRAP, São Paulo, n. 88, p. 2010 ,179-153.

DRAIBE, S. Uma nova institucionalidade das Políticas Sociais? Reflexões a propósito da experiência latino-americana recente de reformas e programas sociais. Sáo Paulo em Perspectiva, v. 11, n. 4, p. 3-15, 1997.

FIAMINI, C.; CALDERON, A. I. Exame Nacional de Desempenho de Estudantes (ENADE): Uma análise à luz da cobertura da Folha de São Paulo (2003-2010), Revista Funadesp, v.5, n. 91, 2012.

GOMES, A. M. Política de avaliaçáo no Brasil: pontuando uma história de açóes. Educaçáa \& Sociedade, Campinas, v. 23, n. 80, p. 275-298, 2002.

GOMES, A. M. Exame Nacional de Cursos e Política de Regulação Estatal no Ensino Superior. Cadernos de pesquisa (Fundação Carlos Chagas), São Paulo, v. 120, p. 2003 , 149-129.

GOUVEIA, A. B.; SILVA, A. A.; SILVEIRA, A.D.; JACOMINI, M. A.; BRAZ, T.P. Trajetória da Avaliação da Educação Superior no Brasil: singularidades e contradiçóes (1983-2004). Estudos em Avaliaçáo Educacional, v. 16, n. 31, 2005.

GUIA DO ESTUDANTE. USP e PUC Minas são consagradas as melhores universidades do ano, na VII ediçáo do Prêmio Melhores Universidades GE, 2011. Disponível em: <http://guiadoestudante.abril.com.br/premio/noticia/usp-puc-minas-recebem-premio-melhores-universidades-ano-642571.shtml> Acesso em: 12 dez. 2013.

HENRIQUE, K. Administraçáo e Ciências Contábeis foram estrelados em ediçáo direcionada para estudantes de todo o país. Sua Carreira FESP. 15 set. 2011. Disponível em: <http://www.suacarreirafesp. com.br/?p=497>. Acesso em: 08 out. de 2013. 
KING, D. O Estado e as estruturas sociais de bem-estar. Novos Estudos CEBRAP, 22, São Paulo, 1988.

LAVAL, C. A Escola náo é uma empresa: o neoliberalismo em ataque ao ensino público. Contrafogos: táticas para enfrentar a invasão neoliberal. Londrina: Editora Planta, 2004.

LEITE, Denise. Ameaças pós-rankings, sobrevivência das CPAs e da auto-avaliação. Avaliaçáo, Campinas; Sorocaba, SP, v.13, n. 3, p. 833-840, 2008.

LIMA, L. C.; AZEVEDO, M. L. N.; CATANI, A. M. O processo de Bolonha, a avaliação da educação superior e algumas consideraçóes sobre a Universidade Nova. Avaliação, Campinas/Sorocaba, v.13, n.1, p.7-36, 2008.

LORENÇO, H. da S. Os rankings do guia do estudante na educaçáo superior brasileira: um estudo sobre as estratégias de divulgação adotadas pelas instituiçóes que obtiveram o prêmio melhores universidades. Dissertação (Mestrado em Educação). Pontifícia Universidade Católica de Campinas, Campinas, 2014.

MARQUES, F. Peso internacional: Rankings mostram o lugar da pesquisa brasileira no mundo e a posição de nossas universidades em áreas específicas. Pesquisa FAPESP Online, Nov. 2009. Disponível em: <http://revistapesquisa.fapesp.br/2009/11/01/peso-internacional/>. Acesso em: 12 nov. 2013.

MINISTÉRIO DA EDUCAÇÃO. Bases para uma nova proposta de avaliaçáo da Educaçáo Superior. Sistema Nacional de Avaliação da Educação Superior. Brasília: Inep, 2004.

MINISTÉRIO DA EDUCAÇÃO. Censo da educaçáo superior: 2010 - resumo técnico. Brasília: Instituto Nacional de Estudos e Pesquisas Educacionais Anísio Teixeira, 2012.

MOLCK, A. M. Exame Nacional de Desempenho de Estudantes: Impactos nas IES e estratégias de aprimoramento institucional. Um estudo a partir da produção científica brasileira (2004-2010). (Dissertação de Mestrado). Pontificia Universidade Católica de Campinas, Brasil, 2013.

ORDORIKA, I.; GÓMEZ, R. R. El ranking Times en el mercado del prestigio universitario. Perfiles Educativos, v. XXXII n. 129, 2010.

PAIVA, V. Educação e bem-estar. Educaçáo e Sociedade, v.12, n.39, p.161-200, 1991.

PAULA, M. de F. C. de. A inserçáo da universidade na lógica racionalizadora do capital: casos USP e UFRJ. In: SILVA, W. C e (org.). Universidade e sociedade no Brasil: oposição propositiva ao neoliberalismo na educação superior. Niterói: Intertexto; Rio de Janeiro: Quartet, 2001.

PLANETA UNIVERSITÁRIO. Prêmio Guia do Estudante: UnB é a melhor em Ciências Sociais e Humanas. São Paulo, 06 out. 2011. Disponível em:

<http://www.unb.br/noticias/unbagencia/unbagencia.php?id=7229>. Acesso em: 08 out. 2011.

POLIDORI, M. M. Políticas de avaliação da educação superior brasileira: Provão, Sinaes, IDD, IGC e Outros Índices. Avaliaçáo, Campinas; Sorocaba, SP, v.13, n. 3, p. 439-452, 2008. 
PONTIFICIA UNIVERSIDAD CATÓLICA DE SAN PABLO. PUC-SP vence prêmio Melhores

Universidades, do “Guia do Estudante”, 2010. Disponível em: <http://www.pucsp.br/noticia/ puc-sp-vence-premio-imelhoresuniversidadesi-do- $\%$ E2\%80\%9Cguiado-estudante $\%$ E2\%80\%9D>. Acesso em: 13 mar. 2012.

REAL, G. C. M. Avaliação e qualidade no Ensino Superior: os impactos do período 1995-2002. Educaçáo e Pesquisa, São Paulo, v.35, n.3, p.573-584, 2009.

SAMPAIO, H. O setor privado de ensino superior no Brasil: o setor privado. São Paulo: Hucitec, FAPESP, 2000.

SANTOS, B. de S. Pela mão de Alice: o social e o político na pós-modernidade. São Paulo: Cortez, 1995.

SETTON, M. da G. J. Um novo capital cultural: pré-disposições e disposiçôes à cultura informal nos segmentos com baixa escolaridade. Educaçáo \& Sociedade, Campinas, v.90, n.26, p.77-105, 2005.

SOUZA, S. Z. L. e OLIVEIRA, R. P. Políticas de avaliação da educação e quase mercado no Brasil. Educaçáo e Sociedade, v.24, n.84, p.723-726, 2003.

TUYAMA, L. Guia do Estudante aponta UFSC como a sétima melhor universidade pública do Brasil. Agecom, UFSC, 14 de out. 2011. Disponível em: <http://portal.reitoria.ufsc.br/2011/10/31/guia-do-estudante-aponta-ufsc-como-a-setima-melhor-universidade-publica-do-brasil/>. Acesso em: 20 mar. 2015.

UNIVERSIDADE BRAZ CUBAS. Cursos da UBC estáo entre os melhores do Brasil, segundo Guia do Estudante. 2012. Disponível em:

$<$ http://www.vestibular.pucgoias.edu.br/index.php?option=com_content\&view=article\&id=213\&Itemid=129>. Acesso em: 14 mar. 2012.

UNIVERSIDADE DE BRASÍLIA. FAC é destaque no Guia do Estudante da Editora Abril. 2011. Disponível em: <http://www.fac.unb.br/site/index.php?option=com_content\&view=category\&layout=blog\&id=67\&Itemid=167>. Acesso em: 02 mar. 2012.

UNIVERSIDADE DO NORTE DO PARANÁ. UNOPAR é destaque no Guia do Estudante. 2011. Disponível em: <http://www2.unopar.br/eventos/guia-estudante-2011.jsp>. Acesso em: 09 out. 2011.

UNIVERSIDAD ESTADUAL PAULISTA JÚLIO DE MESQUITA FILHO. Universidade aparece em primeiro lugar em avaliação feita pela revista Playboy, 2000. Disponível em: <http://www.unesp.br/aci/ jornal/151/ranking.htm>. Acesso em: 13 mar. 2015.

VERHINE, R. E.; DANTAS, L. M. V.; SOARES, J. F. Do Provão ao ENADE: uma análise comparativa dos exames nacionais utilizados no Ensino Superior Brasileiro. Ensaio: Avaliaçáo e Políticas Públicas em Educaçáo, v.14, n.52, p. 291-310, 2006. 